\title{
The Production and the Intercultural Communication of the Cultural Symbols of Confucianism in Japanese Hot-Blood Anime: A Case Study of Naruto
}

\author{
Yixiao Zhang \\ Faculty of Arts and Humanities, King's College London, London, WC2R 2LS, United Kingdom \\ Corresponding author.Email: yixiao.zhang@kcl.ac.uk
}

\begin{abstract}
Japanese anime had made a significant impact on Chinese population, entering and dominating the market after the adoption of the opening-up policy and the one-child policy of China. For a long time, research on the circulation of Japanese anime in China has tended to focus on their use of Chinese elements, mainly objectified elements rather than abstract elements like Chinese philosophy. In order to deal with this understated element, this project will focus on cultural symbols of Confucianism that are produced in Japanese hot-blood anime, adopting Stuart Hall's Encoding/ decoding theory to examine the way these symbols are encoded and decoded through different forms.
\end{abstract}

Keywords: Japanese Hot-blood anime, Naruto, Confucianism, Cultural symbols, Intercultural communication

\section{INTRODUCTION}

\subsection{Background}

This project will focus on the production and the overseas communication of the cultural symbols of Confucianism in Naruto, one of the most popular and influential amines in the 2000s. Its tremendous success not only within the border of Japan but in China indicates certain underneath social and cultural interrelationships between two countries. Many kinds of research on Japanese anime have focused on their utilization of Chinese elements, though mostly objectified elements such as Chinese food, costumes, and arts, examining the cultural proximity and other important factors that contribute to their efficacious exportation to China. It is commonly known that Naruto has clearly adopted many Chinese elements such as traditional costumes, folktales, and martial arts. However, metaphorical Chinese elements such as Chinese philosophy has long been neglected and understated within related research. In order to probe into the underlying factors that made Naruto phenomenal in China and investigate its use of Chinese philosophical elements, this essay will select specific scenes to discuss and analyze them with the help of Stuart Hall's Encoding/decoding theory.

\subsection{Literature Review}

1.2.1. The Intercultural communication of Japanese Hot-blood anime in China

\subsubsection{Reasons for successful dissemination of Hot- Blood Japanese anime in China}

Many scholars like Chen (2010)0 and Yu (2016)0 tend to contribute the enormous success of Japanese Hotblood anime in China to the similarity between Japanese culture and Chinese culture. Historically, traditional Japanese culture was a transplanted culture, influenced profoundly by ancient China. To be more specific, Zhao (2020)0 categorizes these cultural impacts into four aspects, Confucianism, art, Chinese characters, and Buddhist ideologies. Among them, Chinese art is the most ubiquitous Chinese element commonly seen in Japanese anime and the most spotlighted in related research. By contrast, for Chen (2010)0, it is cultural differences that accelerate the intercultural communication considering that Chinese audiences would have a sense of yearning and enchantment for foreign culture during the process of embracing the anime. 
Apart from cultural approximation, the resemblance of social structure of two countries also contributes to the anime mania in China. Feng and Sun (2014)0 claimed that after the economic reformation in the 1980s, China had the same tendency of low fertility rate as Japan. The proclivity of the increasing aging population and the decline of the new-born has made young people in both countries enamoured by the concept of dreams, friendship, adventure, and victory, which was saturated in hot-blood anime that fulfil their spiritual demand and arouse resonance.

Moreover, some also suggest that the national character of Japanese race contributes to the success of the exportation of anime. For example, Wang (2014)0 summarized that their willingness to learn, profound etch of Chinese culture, their insistence of national spirit is consequential for the achievements of Japanese anime in communication.

\subsubsection{Application of Chinese elements in Japanese Anime}

In retrospect of the trajectory of Japanese anime, it seems to have been intimately linked with the element of Chinese culture from its inchoate stage. From Noburo Ofuji's The Story of the Monkey King (1926), which was inspired by the traditional Chinese legend Monkey King, to the first Japanese color animated film The White Snake Enchantress (1958) adapted from the Chinese folk tale Baishe Zhuan, the popularity and pervasiveness of the application of Chinese elements in Japanese anime have intrigued many intercultural researchers. According to Hao (2018)0, the utilization of these elements can be mainly summarized into three modes: surface, inherence and nestification. Liu (2014)0 further refined the categorizations and concluded four ways of applying Chinese elements: direct reconstruction, selective representation, extracting quintessence and deliberate distortion. In addition, Cai (2012)0 considers that the most common elements used in Japanese anime are food, legends, yin yang and traditional architecture. Besides, there are some specific case studies on Chinese elements appropriated in Japanese anime, for instance, Wang (2014)0 analyzed the costumes, weaponry, music and musical instruments in The Story of Saiunkoku while Li (2016)0 investigates martial arts, traditional costumes and fairy tales in Naruto. However, elements examined in these researches are primarily objectified rather than abstract cultural symbols such as Chinese philosophy. Exerting remarkable impacts on Japanese culture, Chinese philosophy and traditional schools of thought are downplayed and understated in many intercultural studies related to anime.

In conclusion, the majority of studies on the adoption of elements of Chinese culture in Japanese anime predominantly aimed to categorize the elements that are most frequently used instead of exploring the deeper meaning of the influence and effects of these cultural symbols in the context of intercultural communication. In addition, researchers generally tend to focus on elements that are materialized, neglecting the abstract symbols such as Chinese philosophy. Thereby, this essay will focus on the cultural symbols of Confucianism in Naruto and examine the ways of encoding Confucian thoughts and the decoding of Chinese audiences.

\subsubsection{The production of Confucian cultural symbols in media}

Confucianism is a system of belief and a way of governing originating in ancient China, which later thrived and developed in proximate east Asian countries such as Korea and Japan during the last several centuries and helped to lay foundations for latter cultures. The cultural symbols of Confucianism are ubiquitous in many visual medias such as TV drama and films in East Asia, intriguing many scholars to study its use and effect in cultural interrelations. However, studies found about the cultural symbols of Confucianism are scarce regarding Japanese films, especially Japanese anime. In this case, studies on similar research interest about other East Asian countries is significant to understand the use of Confucian cultural symbols in Japanese anime. Scholars like Lu Hongmei (2008)0, who are interested in the use of traditional artistic elements in Chinese animated film, pointing out that the thought of Confucianism has always been a latent gene lurking in Chinese animation due to their representation of "Zhongheguan" (Golden Mean) in the narrative and the pedagogical purpose of "Zaidao" (express thoughts) and "Jiushi" (save the world).

Besides, there is an increasing number of studies on Korean TV dramas focusing on their representation of Confucian values due to its recent rise in Asia. For example, Chen (2015)0 thought that the Confucian idea of "Zhongxiao" (loyalty and filial piety), "Ren" (benevolence) and "Li" (rituals and rules) have penetrated in Korean drama. Additionally, Zhao and Zhu (2018)0 used the example of Reply 1988 to study the phenomenon of the intercultural communication of Confucian values. Gao (2018)0 further concluded that the Confucian values embedded in Korean TV series and films encompass Xiao in the ethics of the family, Ren in the morality of the society, the traditional norm of marriage, patriotism, and nationalism. Despite that, he also investigated the underneath impulse and cause of the orientation of Confucian values of Korean TV drama, summarizing that the system of core values, which includes the confidence of national culture, the determination to develope economy, and the indoctrination of morality is key to their insistence and espouse of the penetration of Confucian values. With regard to the similar adherence to rite, morality and core values of Japan, the discoveries of Gao could be 
enlightening to fathom the reasons behind the application of cultural symbols of Confucianism in Japanese anime.

Furthermore, although studies focused on Confucian values in Japanese anime are highly limited in the west, there are still some scholars who recognized the influences of Confucianism on Japanese anime. According to Born (2010)0, Shonen anime like Naruto and Bleach, which focused on friendship, dreams, selfrealization and personal mental struggle, have inherited traditional Confucian thoughts whereas differ from it due to the current social condition and the emergence of subculture in Japan. He linked the indoctrination of core values of Confucianism, such as benevolence, justice and integrity penetrated profoundly in the narrative of Hotblood anime, with the desire of post-war Japanese to rebuild a harmonious and peaceful society upon the ruins of spiritual infertility and barrenness.

\subsubsection{Encoding and Decoding Model of Stuart Hall}

In the study of the production and communication of cultural symbols, the Encoding/decoding Theory proposed by Cultural Study Theorist Stuart Hall is a handy theoretical tool. He perceives a series of actions of collecting, manufacturing, sifting, and coining the information of the mass media as the most pervasive encoding activities. According to Hall, the decoder will experience a process of deciphering the input of the encoder with three distinctive decoding modes: the dominant mode, the negotiated mode, and the oppositional mode. In contrast to the traditional linear mode of communication, the encoding and decoding model could be considered as circular, involving twice transition of structures of meaning because of the potential disparity in cognition between the encoder and the decoder resulted from their different social, cultural, and historical backgrounds.

A few studies of encoding and decoding model reevaluate the theory of Stuart Hall with taking the current context and social condition into account, unearthing and reaffirming its contemporary academic values. For instance, Chen (2014)0 and Huang (2016)0 respectively combed through the historical evolution of the theory, pointing out the misconstruction and impediment it was confronted in China. In addition, a number of scholars attempt to concentrate on the pragmatic utilization of the model in China, for example, Chen (2013)0 and Zhou (2016)0 based their analysis of the audience on Hall's model. Furthermore, other researchers such as Yuan (2013)0 tried to focus on the application of the theory in the field of intercultural communication.

To enrich the practical application of the theory and to provide an example of its practical use under the context of intercultural communication, this research will present a case study of the Japanese anime --- Naruto.
Investigating the ways of encoding the cultural symbols of Confucianism and discussing the social milieu behind it, this essay will simultaneously analyze the decoding mode adopted by audiences and reveal the interrelation between the form of encoding and the effect of decoding.

\subsubsection{Importance of the research}

Studies on the cultural symbols of Confucianism are not prolific and most of them tend to focus on Korean drama due to its current popularity and puissance in Asia whereas Japan was neglected and underrated in the academia. Although Born recognized the relationship between Shone anime and Confucianism, he did not provide a specific and insightful case study. Furthermore, extant studies concentrated on the application of Chinese elements in Japanese hot-blood anime constrained their scope to the objectified themes and overlook the possible appropriation of abstract elements of Chinese culture. Besides, studies on Encoding/ decoding theory still need more practical examples to prove its efficacy and demonstrate its realistic rather than theoretical values. Therefore, in order to challenge the paradigm and to extend the scope of exploring elements in Japanese anime, this study selects Confucianism, one of the most classic and influential school of thoughts in Chinese culture, as researched theme, examining the ways of encoding and decoding of this symbol during intercultural communication.

\subsection{Research Questions}

This project aims to answer four questions below, attempting to examine the way that cultural symbols of Confucianism are encoded, the underlying relationship between the encoding and the social environment that the author lives in, and the way and the preferences of Chinese audiences decoding the cultural symbols.

Q1: How does Naruto encode the cultural symbols of Confucianism? What is the characteristic in form?

Q2: Is the encoding process influenced by factors such as social backgrounds, the ideologies of the encoder and cultural traditions?

Q3: How does the Chinese audiences decode the cultural symbols of Confucianism in Naruto?

Q4: Which form of encoding is the most accepted by Chinese audiences and Which is the least accepted? Why?

\section{METHODS}

This research will be based on text selected from different episodes of Naruto, collecting the data of the feedback of audiences through 'danmu' (barrage), realtime comments from viewers to fly across the screen like bullets. The sample texts selected from the episodes of Naruto are depended on its implication of various 
Confucian values. They will be presented through screenshots listed in the chart with literal descriptions of their encoding form, interpretations and decoding feedback from the audiences.

\section{RESULT}

This section is consisted of five examples selected from different episodes of Naruto which respectively encode important Confucian values, such as "Ren" (benevolence), "He" (Harmony), "Yi"(Justice), "Yong"(bravery), through lines, characterization and plotting.

Table 1. Example for Confucianism

\begin{tabular}{|c|c|c|c|}
\hline $\begin{array}{c}\text { Encoding } \\
\text { Form }\end{array}$ & Encoding Sample & Encoding Interpretation & Decoding Sample \\
\hline Lines & $\begin{array}{c}\text { "Hokage must } \\
\text { understand Li, Yi, Ren, } \\
\text { Zhi, Xin, Xiao, Ti." } \\
\text { (Episode Two: I am } \\
\text { Konohamaru 16:51 - } \\
16: 55)\end{array}$ & $\begin{array}{c}\text { "Ren, Yi, Li Zhi Xin." } \\
\text { (Benevolence, justice, } \\
\text { courtesy, wisdom and } \\
\text { fidelity.) --- Mencius }\end{array}$ & $\begin{array}{c}\text { Dominating mode: } \\
\text { "This is Chinese Confucian } \\
\text { thoughts." }\end{array}$ \\
& & & "Confucianism is international." \\
& & \\
\hline
\end{tabular}

"Ren,Yi, Li, Zhi, Xin" comes from Mencius, a Confucian classic text, it is the basic moral standard that Confucianism has set for people to be a good person. In this scene, Ebisu directly borrows the original line form Confucian texts and consider it as the prerequisites to become Hokage. This is the first time in Naruto that the unmodified and original Confucian ideas being represented in the anime. Most of the audiences had given positive reactions and adopted a dominating decoding mode, recognizing the origin of the line of the character and accept this form of encoding since it directly takes Confucian thoughts from the original text without any changes and represents it explicitly without any metaphorical expression.

Table 2. Example for Benevolence of Confucianism

\begin{tabular}{|c|c|c|c|}
\hline $\begin{array}{l}\text { Encoding } \\
\text { Form }\end{array}$ & Encoding Sample & $\begin{array}{c}\text { Encoding } \\
\text { Interpretation }\end{array}$ & Decoding Sample \\
\hline $\begin{array}{c}\text { Characterizatio } \\
\mathrm{n}\end{array}$ & $\begin{array}{l}\text { Iruka is the first person who did not choose to } \\
\text { hate Naruto because of Kubi but to understand } \\
\text { his pain and accept him. He shows his } \\
\text { sympathy for the loneliness and suffering of } \\
\text { Naruto as an orphanage. } \\
\text { Iruka: "Because we are the same, no one will } \\
\text { praise me after my parents die, and no one will } \\
\text { accept me. It's really painful, isn't it, Naruto. } \\
\text { You must be very lonely, must be very painful. } \\
\text { Sorry, Naruto, if I can be more reliable, I won't } \\
\text { let you have this kind of memory." (Episode 1: } \\
\text { Uzumaki Naruto!) }\end{array}$ & $\begin{array}{c}\text { The feeling of } \\
\text { commiseration is the } \\
\text { principle of } \\
\text { benevolence. } \\
\text {------ Mencius }\end{array}$ & $\begin{array}{l}\text { Dominant position: } \\
\text { "Iruka saved and cured } \\
\text { Naruto." } \\
\text { "Naruto will become } \\
\text { demonized without } \\
\text { Iruka." }\end{array}$ \\
\hline
\end{tabular}

'Treat other people as you would yourself.', a text from Mencius, is the basic principle of benevolence that Confucius has advocated. This action is in accordance with the value of benevolence in Confucianism. From the feedback of this scene, audiences did not directly recognize the encoding of Confucian thoughts but still adopt a dominating mode to accept and approve the values it delivered. 
Table 3. Example for Benevolence of Confucianism

\begin{tabular}{|c|c|c|c|}
\hline Encoding Form & Encoding Sample & Encoding Interpretation & Decoding Sample \\
\hline Plotting & $\begin{array}{l}\text { Kakashi sets up a test for Naruto, } \\
\text { Sasuke and Sakura to make them } \\
\text { choose between obeying the rules } \\
\text { and giving up their companions. } \\
\text { Kakashi: "In the ninja world, } \\
\text { people who break the rules are } \\
\text { scumbags, but people who don't } \\
\text { understand their companions are } \\
\text { scumbags among scumbags. " } \\
\text { (Episode five: Failing, Kakashi's } \\
\text { conclusion, } 20: 28-20: 39 \text { ) }\end{array}$ & $\begin{array}{l}\text { If a man be without the } \\
\text { virtues proper to humanity, } \\
\text { what has he to do with the } \\
\text { rites of propriety? If a man } \\
\text { be without the virtues proper } \\
\text { to humanity, what has he to } \\
\text { do with music?" } \\
\text {---- The Analects of } \\
\text { Confucius } \\
\text { In practicing the rules of } \\
\text { propriety, it is harmony that is } \\
\text { prized." } \\
\text {---- The Analects of } \\
\text { Confucius }\end{array}$ & $\begin{array}{l}\text { Dominant position: } \\
\text { "This is classic." } \\
\text { Oppositional position: } \\
\text { "It seems that only } \\
\text { disobeying } \\
\text { the order is the way to } \\
\text { become } \\
\text { qualified." }\end{array}$ \\
\hline
\end{tabular}

$\mathrm{Li}$, namely rituals and rules, is one of the basic principles and standards of Confucianism. Its goal is to regulate people from different hierarchies to reach a state of peace and harmony and to pacify conflicts. In this sense, Li is ultimately served for $\mathrm{He}$ (harmony), emphasizing a state of peace and stability between humans and nature, and between individuals within the society. In this scene, Kakashi uses a test to lecture his students with Confucian values. Different from previous examples, this scene encountered more controversy, audiences adopt two decoding modes, dominating mode and oppositional position. Audiences are unable to recognize the underlying Confucian thoughts, some approving the decisions of Kakashi while others opposing his views.

Table 4.Example for Justice of Confucianism

\begin{tabular}{|c|c|c|c|}
\hline $\begin{array}{l}\text { Encoding } \\
\text { Form }\end{array}$ & Encoding Sample & Encoding Interpretation & Decoding Sample \\
\hline Lines & $\begin{array}{l}\text { Kakashi: "It is cowardice to } \\
\text { see what is right and not to } \\
\text { do it." (Episode 12: Battle } \\
\text { on the bridge,reappearance } \\
\text { of Zabuza, 13:36 -13:42) }\end{array}$ & $\begin{array}{l}\text { It is cowardice to see what } \\
\text { is right and not to do it. } \\
\text {---- The Analects of } \\
\text { Confucius }\end{array}$ & $\begin{array}{l}\text { Dominant position: } \\
\text { "I love the translation." } \\
\text { "It is cowardice to see what is } \\
\text { right not to do it." }\end{array}$ \\
\hline $\begin{array}{c}\text { Characterizati } \\
\text { on }\end{array}$ & $\begin{array}{c}\text { Namikaze Minato: } \\
\text { Yondamei died for his } \\
\text { village in the combat with } \\
\text { Kubi and sacrificed his life } \\
\text { for the peace of and security } \\
\text { of his homeland. "(Episode } \\
469 \text { Thank you!, 12:19 - } \\
12: 36)\end{array}$ & $\begin{array}{l}\text { "Life is what I desire, and so } \\
\text { is righteousness. If I cannot } \\
\text { have them both, I would } \\
\text { choose the latter and } \\
\text { forsake the former. } \\
\text {-----Mencius }\end{array}$ & $\begin{array}{c}\text { Dominant position: } \\
\text { "yondaimei is god!" } \\
\text { "Yondaimei is a hero, a true } \\
\text { genius." } \\
\text { "He died for righteousness." }\end{array}$ \\
\hline
\end{tabular}

Both scenes listed above represent Confucian values, righteousness, and bravery, they are the basic moral standards to become a noble man in Confucianism. According to The Analects of Confucius, behaviors that conform to benevolence can be defined as brave and justice. In this scene, the author directly borrows the original line from classic texts as the lines of Kakashi. The belief that the character holds is in accordance with Confucian ideas. Considering the feedback, many audiences recognized its origin and generally adopts dominant position. In the second scene where Yondaime died for his village, it demonstrates the justice and bravery that Confucianism advocates. However, audiences are unable to recognize its Confucian origin but again take a dominant position.

\section{DISCUSSION}

The cultural symbols of Confucianism in Naruto are mainly encoded through lines, characterizations and plotting, rendered mainly in verbal and non-verbal forms. They are represented through the references to Confucian classical texts and the narrative of the story, encompassing Confucian core values such as benevolence, justice, and bravery. This way of encoding is influenced by the social environment and cultural backgrounds of contemporary Japan. The author Kishimoto Masashi had his own intention and purpose during the process of encoding cultural symbols. For example, he deliberately underlined values such as benevolence, harmony and justice while neglecting other Confucian values such as "Xiaoti" (filiality) which emphasized a sense of hierarchy and rigid orders of 
seniority. The relationship between father and son, teachers and students can be considered as a more equal relationship as friends rather than obedience and complaisance which characterize the relationship between the elder and the younger in Confucian traditions.

Considering that Naruto is serialized in the magazine Shonen Jump whose readers are mainly young people. Its ideologies and values will obviously be oriented depending on the preferences of young people. The contemporary Japanese young people generally feel conflicting with the traditional rigid order and hierarchal system while still embracing values like benevolence and justice which are more consistent with universal values at present. Additionally, Naruto is created during the era of Heisei, a time when Japan had just undergone the economic bubble of the 1990s and entered a long-term depression and stalemate. The name Heisei comes from Shiji (The Grand Scribe's Records), possessing a meaning of harmony and peace. The underlying signification of this name implicates the desires of Japanese for stability and peace. Contrasted to the extravagance and decadence of the Showa era, Heisei era can be characterized as steadiness, diligence, and circumspection which are in accordance with some core values of Confucianism. Therefore, the story of Naruto was clearly echoed with this zeitgeist and at the same time exploited the ideologies of Confucianism.

This transition of Japan from one era to another was paralleled with the economic turn of modern China. After the economic reform and the implementation of the opening-up policy in the 1990s, diverse cultures and products from both neighbouring Asian countries and the west flock over into Chinese society and market. Modern China has experienced a period of cultural prosperity. It is during this period that various Japanese anime have been exported to the Chinese market and became remarkably popular. However, the enforcement of another policy, the one-child policy, dramatically decreased the population of young children. The surge in the aging population and low fertility rate made China similar to Japan in terms of the societal structure. This resemblance has made young people in two nations have similar states of mind, such as loneliness, isolation and the desire for companion, friendship, adventure, and dreams which are all reflected in hot-blood Japanese anime. Therefore, the ideas embedded in the anime are in accordance with the spiritual need and desire of young people in both countries. This can be seen as a major reason, apart from inherent cultural similarity, for the success of Japanese anime in the Chinese market.

From the feedback of the audiences collected from "danmu", the majority of Chinese audiences are able to recognize the cultural symbols of Confucianism directly and deemed that Naruto has adopted a large number of Chinese elements. They mainly adopt the dominant position when they decoded the cultural symbols in the anime, showing positive attitude toward the representation of Confucian values such as benevolence, justice and bravery through the verbal form of encoding like lines that made reference to Confucian classic texts.

It can be noticed that the encoding form will affect the decoding mode that the audiences choose to adopt. When the encoding was made through verbal form, such as borrowing original Confucian texts as lines of the characters, the audiences tended to give positive and immediate reactions and confirmation of its underlying ideas. While when the encoding was approached through non-verbal form, such as the characterization of roles and plot arrangement, the reactions were less satisfactory and unified. This indicates that the encoding of the abstract cultural symbols encounters a more challenging decoding process for the audiences when it demonstrates more metaphorical representations while a more direct and explicit way of rendering can be understood and accepted more immediately and positively.

\section{CONCLUSION}

In conclusion, throng analysing the selected examples from the text, it can be identified that cultural symbols of Confucianism are mainly encoded through three ways, verbal lines, characterization, and plotting. The form of encoding will affect the attitudes and reactions of the audiences and their decoding modes. For verbal form of encoding such as directly borrowing original Confucian texts, the audiences generally adopt dominant positions and identify with the ideas. Differently, the oppositional positions emerge with the non-verbal form of encoding, characterization and plotting since they are more implicit and metaphorical for audiences to discern and decode its underlying Confucian values.

In terms of the limitation of this project, considering the lack of solid and in-depth understanding of Confucianism due to the time limit, the research might be insufficient in some respects. In addition, the channel for audiences to watch Naruto is diverse, the collected data of the feedback of the audiences may not be sufficient and diverse enough since this project only focuses on the official video channel. Besides, the text that this project concentrates is the Chinese version of Naruto rather than the original version in Japanese. The will and the intention of the original author may be altered slightly because of the Chines translation, the loss of some original meanings may be inevitable. For the possible improvement and further investigation, the next step for the research may be an attempt to enrich its data collection and to probe deeper into Confucian thoughts and classics. 


\section{REFERENCES}

[1]C, Qi. Analysis of the cross-cultural communication strategy of Japanese animation in China, News Knowledge, 2010, \{4\} (12): 41-43. http://navi-cnkinet-

443.webvpn.bjmu.tsg211.com/knavi/journals/XW ZS/detail?uniplatform $=\mathrm{NZKPT}$

[2]Y, Di. Cross-Cultural Communication of Japanese Animation in China, Changjiang Series, 2016, \{4\} (26): 36-37. http://navi-cnki-net443.webvpn.bjmu.tsg211.com/knavi/journals/CJC $\mathrm{K} /$ detail?uniplatform $=\mathrm{NZKPT}$

[3]Z, Ting. The Spread and Acceptance of Traditional Chinese Culture in Japanese Anime, China Radio and Television Journal, 2020, \{4\} (08): 74-77. http://navi-cnki-net-

443.webvpn.bjmu.tsg211.com/knavi/journals/GDX $\mathrm{K} /$ detail?uniplatform $=\mathrm{NZKPT}$

[4]F, Zengyu, Sun, Qianqian. The Spread and Acceptance of Japanese Hot Blood Anime in China, Journal of China Communication University, 2016, 38 (04): 76-80.

[5]W, Haiqing. Interpreting the Chinese Elements in Japanese Anime - Take "Color Cloud National Language" as an example, 2014, \{4\} (22): 188.

[6]H, Yuyao. Research on the Application of Chinese Elements in Japanese Animation. Hainan Normal University, 2018.

[7]L, Wen. Chinese Elements in Japanese Anime. Bohai University, 2014.

[8]C, Yanyan. The Use of Japanese Anime to Elements of Chinese Culture and Its Enlightenment, Film Literature, 2012, \{4\} (21): 33-34. http://navi-cnkinet-

443.webvpn.bjmu.tsg211.com/knavi/journals/DYL $\mathrm{X} /$ detail?uniplatform $=\mathrm{NZKPT}$

[9]L, Qi. Exploration of traditional elements of Japanese anime culture in Japanese anime - Take "Naruto" as an example. Business Story, 2016, \{4\} (31): 146$147 . \quad$ http://navi-cnki-net443.webvpn.bjmu.tsg211.com/knavi/journals/SGU S/detail?uniplatform=NZKPT

[10]L, Hongmei. Analysis of traditional artistic elements of Chinese animation. Wuhan University of Technology, 2008.

[11]C, Di. On Confucian Cultural Thoughts and Contemporary Values in Korean Tv Dramas, 2015, $\{4\}$ (23): 81-82.

[12]Z, Qianru, Zhu. Bin. Cross-Cultural Communication in Korean Film and Television Dramas - Take
Confucian Culture as an Example. House of Drama, 2018, $\{4\} \quad$ (02): 61-62. http://navi-cnki-net443.webvpn.bjmu.tsg211.com/knavi/journals/XJZ $\mathrm{T} /$ detail? uniplatform=NZKPT

[13]G, Zhendi. The high flute. Confucian Cultural Complex in Korean TV Dramas. China Academy of Art, 2018.

[14]B, Christopher. In Footsteps of the Master: Confucian Values in Anime and Manga, ASIANetwork exchange, 01 April 2010, Vol.17(2), pp.39-53.

[15]C, Lidan, Lin Yufeng. Inheritance and Innovation: Study stuart Hall's representative work Coding/Decoding. News and Communication Research, 2014, 21 (08): 99-112-128. http://navicnki-net-

443.webvpn.bjmu.tsg211.com/knavi/journals/YAN $\mathrm{J} /$ detail?uniplatform $=\mathrm{NZKPT}$

[16]H, Dianlin. The Yellow Forest. Rereading "The Coding and Decoding of Television Discourses" - A Methodological Contribution to the Study of Media Culture by Stuart Hall. News and Communication Research, 2016, 23 (05): 58-72+127.

[17] C, Yuefen. Weibo users probed into how disaster information was decoded - take "July 21 Beijing Rainstorm" as an example. Jinan Journal, 2013, 35 (06): $\quad 150-155+164$. http://navi-cnki-net443.webvpn.bjmu.tsg211.com/knavi/journals/JNX $\mathrm{B} /$ detail?uniplatform $=\mathrm{NZKPT}$

[18]Z, Ya. Audience's "Carnival" in the Impeachment Screen - Analysis Based on Stuart Hall's Coding/Decoding Theory. China Media Technology, 2016, \{4\} (07): 68-69+75. http://navicnki-net-

443.webvpn.bjmu.tsg211.com/knavi/journals/CM $\mathrm{KJ} /$ detail?uniplatform=NZKPT

[19]Y, Shuai. Cross-Cultural Communication of Chinese Elements in Movies - Case Study based on kungfu Panda, Film Literature, 2013, \{4\} (08): 44-45. http://navi-cnki-net-

443.webvpn.bjmu.tsg211.com/knavi/journals/DYL $\mathrm{X} /$ detail?uniplatform $=\mathrm{NZKPT}$ 